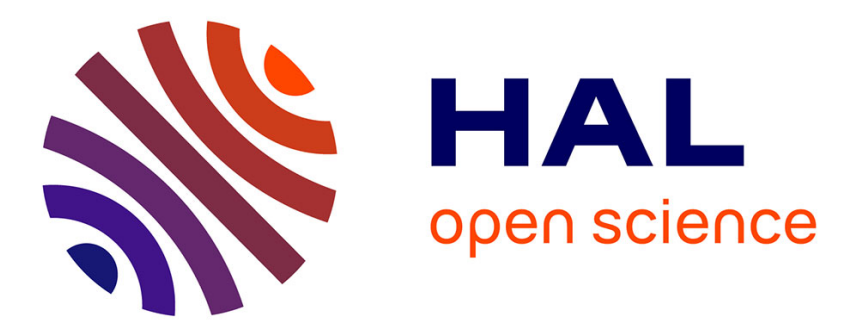

\title{
Higher nutritional quality at no additional cost among low-income households: insights from food purchases of "positive deviants"
}

Lucile Marty, Christophe Dubois, Malu S Gaubard, Audrey Maidon, Audrey

Lesturgeon, Hind Gaigi, Nicole Darmon

\section{To cite this version:}

Lucile Marty, Christophe Dubois, Malu S Gaubard, Audrey Maidon, Audrey Lesturgeon, et al.. Higher nutritional quality at no additional cost among low-income households: insights from food purchases of "positive deviants". The American Journal of Clinical Nutrition, 2015, 102 (1), pp.190 - 198. 10.3945/ajcn.114.104380 . hal-01785454

\section{HAL Id: hal-01785454 \\ https://hal-amu.archives-ouvertes.fr/hal-01785454}

Submitted on 4 May 2018

HAL is a multi-disciplinary open access archive for the deposit and dissemination of scientific research documents, whether they are published or not. The documents may come from teaching and research institutions in France or abroad, or from public or private research centers.
L'archive ouverte pluridisciplinaire HAL, est destinée au dépôt et à la diffusion de documents scientifiques de niveau recherche, publiés ou non, émanant des établissements d'enseignement et de recherche français ou étrangers, des laboratoires publics ou privés.

\section{(c)(1)}

Distributed under a Creative Commons Attribution| 4.0 International License 


\title{
Higher nutritional quality at no additional cost among low-income households: insights from food purchases of "positive deviants"1,2
}

\author{
Lucile Marty, Christophe Dubois, Malu S Gaubard, Audrey Maidon, Audrey Lesturgeon, Hind Gaigi, and Nicole Darmon*
}

Unité Mixte de Recherche (UMR) "Nutrition, Obesity and Risk of Thrombosis," Institut National de la Recherche Agronomique (INRA) 1260, Institut National de la Santé et de la Recherche Médicale (INSERM) 1062, University of Aix-Marseille, Marseille, France

\begin{abstract}
Background: It is unknown whether diet quality is correlated with actual food expenditure. According to the positive deviance theory, the study of actual food expenditure by people with limited economic resources could help identify beneficial food-purchasing behavior.

Objectives: The aims were to investigate the relation between actual expenditure on food and nutritional quality and to identify "positive deviants" among low-income households.

Design: Individuals in deprived social situations $(n=91)$ were recruited as part of the "Opticourses" nutrition intervention conducted in 2012-2014 in poor districts of Marseille, France. Opticourses participants collected food-purchase receipts for their household over a 1-mo period. "Actual diet costs" and "estimated diet costs" were calculated per $2000 \mathrm{kcal}$ of food purchases by using actual expenditures and a standard food price database of food consumed by a representative sample of French adults, respectively. Mean adequacy ratio (MAR), mean excess ratio (MER), and energy density (ED) were used as nutritional quality indicators. "Positive deviants" were defined as having a higher MAR and a lower MER than the respective median values. Results: Opticourses participants selected less-expensive food options than the average French population, both within a food group and for a given food item. Higher diet costs were associated with higher nutritional quality (higher MAR, lower ED), regardless of whether costs were calculated from actual expenditure or on the basis of standard food prices. Twenty-one positive deviants were identified. They made significantly healthier purchases than did other participants (MAR: $+13 \%$; MER: $-90 \%$. ED: $-22 \%$ ) at higher estimated diet costs. Yet, they did not spend more on food (having the same actual diet costs), which showed that they purchased food with a higher nutritional quality for their price.

Conclusion: In this low-income population, actual diet cost was positively correlated with nutritional quality, yet the results showed that higher diet quality is not necessarily more costly when foods with higher nutritional quality for their price are selected. The Opticourses intervention was registered at clinicaltrials.gov as NCT02383875. Am J Clin Nutr 2015;102:190-8.
\end{abstract}

Keywords: nutrition economics, food expenditure, nutritional quality, low income, positive deviance

\section{INTRODUCTION}

Cross-sectional epidemiologic studies have always shown a positive association between diet quality and diet cost, re- gardless of the country (1-5) or of a population's socioeconomic status $(6,7)$. Lower incomes are generally associated with lower diet costs and lower quality diets $(4,8,9)$. The social gradient in diet quality may therefore be explained by the high cost of healthy diets (10), and so the higher cost of more nutritious diets may contribute to socioeconomic disparities in health (11).

In a precursory study, McAllister et al. (12) showed that healthier diets usually but not necessarily cost more. In selfselected diets they observed a positive association between diet quality and diet cost, but they also showed that healthy diets can be designed at a moderate cost and need not be more expensive (12). An overall positive relation between diet quality and diet cost was observed in the United States among women in the Nurses' Health Study, but large interindividual variability was found, with some women in the lowest quintile of daily diet cost having healthy diets (3). In the NHANES, US adults from some ethnic groups were shown to consume lower-cost yet higher-quality diets (4, 13). This is reminiscent of the positive deviance theory that emerged in the 1970s for community education (14). It is predicated on the observation that even in "at risk" situations, there are some individuals or households, called "positive deviants," with uncommon but beneficial behavior, leading to adequate food security, housing, or health (14). In the field of nutrition, dietary patterns of positive-deviant individuals could provide insights into how appropriate consumption can be achieved in an unfavorable context, such as with limited economic resources, cultural pressures, or low educational standards (15).

The variability in food choices and food expenditure is the key to identifying the best food pattern to reach nutritional recommendations under budget constraints. Unfortunately, the studies

\footnotetext{
${ }^{1}$ Supported by the French National Cancer Institute (INCA) and the Regional Agency for Health in Provence-Alpes-Côte d'Azur. This is a free access article, distributed under terms (http://www.nutrition.org/publications/ guidelines-and-policies/license/) that permit unrestricted noncommercial use, distribution, and reproduction in any medium, provided the original work is properly cited.

${ }^{2}$ Supplemental Table 1 is available from the "Supplemental data" link in the online posting of the article and from the same link in the online table of contents at http://ajcn.nutrition.org.

*To whom correspondence should be addressed. E-mail: nicole.darmon@ univ-amu.fr.

Received November 29, 2014. Accepted for publication April 30, 2015.

First published online May 27, 2015; doi: 10.3945/ajcn.114.104380.
} 
on the link between diet costs and nutritional quality did not use actual food expenditures but instead used standard food price databases, computed from prices paid by a national panel $(1,2,4)$ or from local supermarket retail prices $(6,8)$. Yet, a number of studies have shown the feasibility and accuracy of using cash register receipts to assess actual expenditure and food patterns of households (16-20).

Thus, in previous studies, the relation between diet costs and the nutritional quality of diets was always explored by using standard food prices (1-7), and when food expenditure was recorded, its association with indicators of diet quality was never explored (16-19). In the present study, we used food-purchase cash register receipts for a 1-mo period, collected as part of the baseline assessment of a nutrition intervention conducted in a low-income population, to test whether the positive relation observed between diet cost and nutritional quality is confirmed when diet cost is estimated from actual expenditure. In addition, the present study aimed at exploring the variability in food-purchasing behavior to identify "positive deviants" among low-income households.

\section{METHODS}

\section{The Opticourses intervention}

Data for the present study were collected as part of the baseline assessment of the Opticourses nutrition intervention (21), which aims to improve the nutritional quality of food purchases under budgetary constraints. The criteria for households to be included in the study were willingness to be involved in an intervention session, consisting of five 2-h workshops, and living in the northern districts of Marseille. These districts are socioeconomically deprived, with very low incomes, heavy financial dependence on social benefits, and overrepresentation of individuals covered by free social security. The workshops were based on the individuals' actual food purchases and, notably, on their cash register receipts. During the 5 worshops, the receipts were used as intervention tools: participants and research staff discussed the receipts brought in by all participants and exchanged ideas and experiences around food-purchasing behaviors. Over $2 \mathrm{y}$, between September 2012 and September 2014, 91 participants kept a detailed record of the quantities of food entering their household over $1 \mathrm{mo}$, including purchases, gifts, and from other sources. During 1 of the 5 workshops, each participant had a face-to-face interview to answer questions related to their household, particularly how they perceived their financial situation. All participants provided written informed consent to participate in the study and were compensated for collecting their food purchase receipts. No institutional review board approval was necessary for this research, as stated by the Comité de Protection des Personnes Sud-Méditerranée, which reviewed the protocol of the Opticourses education intervention. This trial was registered at clinicaltrials.gov as NCT02383875.

\section{Food-composition database and "standard food price database"}

Food product nutrient composition was obtained from the national food database created by ANSES (French Agency for Food, Environmental and Occupational Health Safety), which includes 1343 food items declared as consumed by a represen- tative sample of 2624 adults participating in the 2006-2007 national dietary survey Individuelle Nationale des Consommations Alimentaires (INCA2) (22). Drinking water was excluded from all analyses because it is not necessarily purchased. All remaining foods were aggregated into 9 groups and 29 categories. For instance, the "nuts," "vegetables," and "fruit" categories (including fruit juices) were combined into the "fruit and vegetables" group.

A "standard food price database" was obtained by estimating the standard price of each of the 1343 INCA2 food items from the 2006 Kantar-World Panel purchase database (23), which gives the annual expenditure and quantity purchased of food products registered through the use of bar codes by a representative sample of 12,000 French households. For each INCA2 food item, its standard price was calculated by dividing the annual expenditure by the quantities purchased of all of the food products available on the market corresponding to this item in the Kantar-World Panel purchase database. Because these were the prices paid by a representative panel of consumers, the standard prices reflected the most frequently purchased forms of each food. After adjustment for preparation and waste, food prices in the database were expressed in euros $(€)$ per $100 \mathrm{~g}$ of edible portion.

\section{Receipt protocol training and data collection}

At the first workshop, the protocol for receipt collection and annotation was explained to the participants. They were asked to save all receipts for foods consumed at home during a 1-mo period. Foods consumed outside of home were not included. To facilitate data collection, participants were given a notebook of food purchases in which they could find step-by-step instructions, example receipts, and, on the last page, an envelope in which to collect the receipts. In case of incomplete or ambiguous printed information with regard to the name of the store, the name of a food, the quantities purchased, or the price paid for a food, participants were instructed to write it on the receipt. Expenditures without receipts (gifts or from other sources) were to be recorded in the notebook: we also use the term "receipt" to refer to these food items. The participants were also requested to ask other household members to keep their receipts. The second workshop, 2 wk later, provided the opportunity to discuss the receipt collection and to help participants encountering difficulties. At the third workshop, after another $2 \mathrm{wk}$, each participant handed over the notebook of food purchases; it was checked to verify whether there was any missing information, and the notebook was kept for analysis by dietitians. Food waste or meals consumed by visitors were not recorded because Nelson et al. (24) showed that adjustments to purchases for waste are negligible and foods consumed by visitors account for $<0.5 \%$ of average family food energy purchased.

\section{Data record protocol and creation of the "Opticourses food price database"}

When collected, the annotated receipts were entered into a food-purchases database. For each food item, date of purchase, source, the most accurate INCA2 food name and corresponding INCA2 food code, quantity, and price were entered. Not all of the receipts contained the information about the purchased quantity. 
In those instances, 3 methods were used to determine an appropriate estimate of quantity: 1) commercial websites containing databases of foods with detailed quantity descriptions were searched; 2) if the information was not available but the food item was purchased at least twice (with the receipt showing the weights) among all households, we calculated an observed mean food price per unit of weight and then, to estimate the quantity purchased, we divided the price paid for the food item by the corresponding observed mean price; 3 ) if we did not have an observed mean food price, we used the corresponding standard food price in the same way.

We created the "Opticourses food price database," which contains observed mean food prices per unit of weight for foods purchased at least twice among all households with the receipt showing the weights. For cases in which the food consumed was gifted or came from food aid, we calculated a theoretical price using the observed mean food price. For each item, an edible portion was calculated to take into account the changes in weight associated with preparation and waste.

We use the term "diet" to refer to daily purchases per person or per $2000 \mathrm{kcal}$ of purchases. We use "actual diet cost" to refer to the actual amount of money spent by households for their food purchases (i.e., as indicated by the receipts) per person or per $2000 \mathrm{kcal}$. We use the term "estimated diet cost" to indicate the cost of a diet calculated with the standard food price database per person or per $2000 \mathrm{kcal}$.

\section{Data analysis}

\section{Price and type of food purchased}

The price and type of food purchased by the households of Opticourses participants (also called "Opticourses households" below) were analyzed by comparing different ways of calculating the median energy cost (price per $100 \mathrm{kcal}$ ) of 7 food groups. First, the median energy cost was calculated by using the standard prices of all of the food items included in the standard food price database for each food group. Second, the median energy cost was calculated by using the standard prices but only for the food items actually purchased by Opticourses households. Opticourses participants did not purchase all of the food items included in the standard food prices database. Third, the median energy cost was calculated by using only the Opticourses food price database (i.e., by including only the food purchased by the Opticourses households and at the prices paid, on average, by this population).

\section{Diet cost and nutritional quality}

Daily food weight (in g/d per person), daily energy intake (in $\mathrm{kcal} / \mathrm{d}$ per person), and daily nutrient intake (in $\mathrm{g}, \mathrm{mg}$, or $\mu \mathrm{g} / \mathrm{d}$ per person) were estimated for each household by summing the edible weight and the energy or the nutrient content of all foods and beverages purchased and dividing by the number of days of data collection and the number of household members.

\section{Actual diet cost and estimated diet cost}

The actual diet cost (in $€ / d$ per person) was calculated for each household by summing receipt prices of all foods and beverages purchased and dividing by the number of days of data collection and the number of household members. The estimated diet cost (in $€ / d$ per person) was calculated with the standard food price database, by multiplying the edible weight of each food and beverage by its unit cost, summing over all foods and beverages purchased, and dividing by the number of days of data collection and the number of household members. The actual and estimated diet costs per $2000 \mathrm{kcal}$ were also calculated.

\section{Dietary energy density}

High dietary energy density $(\mathrm{ED})^{3}$ is an indicator of poor nutritional quality $(25,26)$. ED (in kcal/100 g) was calculated by dividing the total energy provided by solid foods (including soups) by their total edible weight. As suggested by Ledikwe et al. (27), foods typically consumed as beverages (e.g., milk, juices, and soft drinks) were not included in the calculation of ED.

\section{Mean adequacy ratio}

The mean adequacy ratio (MAR) was used as an indicator of nutritional adequacy (28). It was calculated as proposed by Maillot et al. (29) as the mean percentage of the recommended intakes for 23 nutrients (proteins, fiber, linoleic acid, linolenic acid, DHA, vitamin A, thiamin, riboflavin, niacin, vitamin B-6, folates, vitamin B-12, ascorbic acid, vitamin E, vitamin D, calcium, potassium, iron, magnesium, zinc, copper, iodine, and selenium) as follows:

$$
M A R=\frac{1}{23} \times\left(\sum_{n=1}^{23} \frac{\text { Quantity }_{n}}{R D A_{n}} \times 100\right)
$$

Quantity $_{n}$ is the quantity of each nutrient per $2000 \mathrm{kcal}$ of purchases and $\mathrm{RDA}_{n}$ is the French Recommended Dietary Allowance (RDA) (30) for that nutrient (mean for men and women). Each ratio (Quantity ${ }_{n}: \mathrm{RDA}_{n}$ ) was limited to 1 , so that a large quantity of 1 nutrient could not compensate for a small quantity of another (31).

\section{Mean excess ratio}

The mean excess ratio (MER) was used as an indicator of nutrients to be restricted (32). It was developed by Vieux et al. (32) by analogy with the MAR as the mean percentage of maximum recommended values (MRVs) for 3 harmful nutrients $(h n)$, namely SFAs, sodium, and free sugars, as follows:

$$
M E R=\left[\frac{1}{3} \times\left(\sum_{h n=1}^{3} \frac{\text { Quantity }_{h n}}{M R V_{h n}} \times 100\right)\right]-100
$$

Quantity $_{h n}$ is the intake of each harmful nutrient per 2000 kcal of purchases. Free sugars include sugars naturally present in honey, syrups, and fruit juices and added sugars (33). The MRVs for SFAs and free sugars correspond to $10 \%$ of an energy intake of $2000 \mathrm{kcal}$ (i.e. 22.2 and $50 \mathrm{~g}$, respectively). The MRV for sodium was $3153 \mathrm{mg}$ and corresponded to an intake of $8 \mathrm{~g} \mathrm{NaCl}$.

\footnotetext{
${ }^{3}$ Abbreviations used: ED, energy density; INCA, Individuelle Nationale des Consommations Alimentaires; MAR, mean adequacy ratio; MER, mean excess ratio; MRV, maximum recommended value; RDA, Recommended Dietary Allowance.
} 
Each ratio (Quantity ${ }_{h n}: \mathrm{MRV}_{h n}$ ) $<1$ was set to 1 , so that a low intake of 1 harmful nutrient could not compensate for the high intake of another.

\section{Identification of "positive deviants"}

The method for classifying households on the basis of the nutritional quality of their purchases was inspired by Vieux et al. (32). MAR and MER per $2000 \mathrm{kcal}$ of purchases were calculated for each household. Households were then ranked according to the value of these 2 indicators compared with their observed median. High-nutritional-quality purchases met with the 2 following criteria: MAR above the median and MER below the median. We refer to the households with such purchases as "positive deviants."

\section{Statistical methods}

Nonparametric statistics were used because diet variables were not normally distributed in this small sample of households. Wilcoxon's Matched-Pairs Signed Rank test and Spearman correlation were used for paired comparison and for correlations between variables, respectively. Wilcoxon two-sample test was used to compare quantitative variables of 2 independent groups and chi-square test was used to compare qualitative variables. An $\alpha$ level of 0.05 was chosen to determine statistical significance. Statistical analyses were performed by using SAS software version 9.4 (SAS Institute).

\section{RESULTS}

\section{Opticourses households: descriptive characteristics}

Seventy-six percent of the Opticourses participants were female. Opticourses households had 3 or 4 people on average [1.8 (range: $1-7$ ) adults and 1.7 (range: $0-6$ ) children], but $18 \%$ of participants lived alone ( $81 \%$ male and $19 \%$ female) and $25 \%$ of households comprised single women with children. The mean $( \pm \mathrm{SD})$ age of Opticourses participants was $48.1 \pm 10.1 \mathrm{y}$. Only $15 \%$ reported being in a stable financial situation, $48 \%$ were in a precarious financial situation, and $37 \%$ had severe financial difficulties. Ten households consisted of food aid recipients (i.e.,
$11 \%$ of the studied sample); food aid represented, on average, $30 \% \pm 25 \%$ of their energy intake (data not shown). On average, each household shopped at 5 different stores to buy food while collecting receipts.

We identified 21 positive-deviant households. Table 1 shows that there was no difference in descriptive characteristics between positive deviants and other households. Household composition, the number of stores patronized, and the financial situation of the 2 groups were similar.

\section{Price and type of food purchased by Opticourses households}

A total of 9742 food items were purchased by Opticourses households and included in the food-purchases Opticourses database. The mean $( \pm S D)$ number of days between the first and last receipt provided by households was $28.4 \pm 17.1 \mathrm{~d}$. Figure 1 shows that the median energy costs of the "fruit and vegetables" and the "meat, fish, and eggs" groups were significantly lower when they were calculated by considering only the food bought by the Opticourses households and not all of the food present in the standard food database. This means that Opticourses households chose the less-expensive options within those 2 specific food groups but not within the other food groups. Figure 1 also shows that, within each food group, the median energy costs were significantly lower with Opticourses prices than with standard prices, except for starchy foods, which showed that Opticourses households also selected less-expensive options of the same food item. Yet, we observed the same hierarchy of food groups in terms of energy costs. Indeed, fruit and vegetables remained the most expensive energy source, whereas fats remained the least expensive, no matter how the median energy cost was calculated.

Spearman correlations between standard energy costs and Opticourses energy costs were performed for all foods purchased by Opticourses households and within each food group. All correlations were significant (data not shown), showing the same ranking of food prices for both Opticourses and standard food prices.

TABLE 1

Sociodemographic characteristics of Opticourses households

\begin{tabular}{|c|c|c|c|c|c|c|c|}
\hline & \multicolumn{2}{|c|}{ All $(n=91)$} & \multicolumn{2}{|c|}{ Positive deviants $^{1}(n=21)$} & \multicolumn{2}{|c|}{ Others $(n=70)$} & \multirow[b]{2}{*}{$P$} \\
\hline & Mean \pm SD & Median (IQR) & Mean \pm SD & Median (IQR) & Mean \pm SD & Median (IQR) & \\
\hline Respondent age, $\mathrm{y}$ & $48.1 \pm 10.1$ & $48(42-55)$ & $52.0 \pm 11.2$ & $52(46-58)$ & $46.8 \pm 9.42$ & $47.5(41-53)$ & $0.053^{2}$ \\
\hline Household members, $n$ & $3.41 \pm 1.97$ & $3(2-5)$ & $3.24 \pm 2.00$ & $3(2-5)$ & $3.46 \pm 1.96$ & $3(2-5)$ & $0.62^{2}$ \\
\hline Children, $n$ & $1.70 \pm 1.68$ & $2(0-3)$ & $1.75 \pm 1.86$ & $1(0-3.5)$ & $1.69 \pm 1.63$ & $2(0-3)$ & $0.94^{2}$ \\
\hline Stores, $n$ & $4.85 \pm 3.22$ & $4(2.5-6.5)$ & $5.42 \pm 4.05$ & $5(2-8)$ & $4.69 \pm 2.95$ & $4(3-6)$ & $0.71^{2}$ \\
\hline Female respondents, $\%$ & \multicolumn{2}{|c|}{77} & \multicolumn{2}{|c|}{81} & \multicolumn{2}{|c|}{74} & $0.53^{3}$ \\
\hline Food aid recipients, \% & \multicolumn{2}{|r|}{11} & \multicolumn{2}{|c|}{14} & \multicolumn{2}{|r|}{10} & $0.58^{3}$ \\
\hline Financial situation, $\%$ & & & & & & & $0.47^{3}$ \\
\hline Stable & \multicolumn{2}{|r|}{15} & \multicolumn{2}{|c|}{20} & \multicolumn{2}{|r|}{14} & \\
\hline Precarious & \multicolumn{2}{|c|}{48} & \multicolumn{2}{|c|}{40} & \multicolumn{2}{|r|}{51} & \\
\hline Severe difficulties & \multicolumn{2}{|c|}{37} & \multicolumn{2}{|c|}{40} & \multicolumn{2}{|r|}{35} & \\
\hline
\end{tabular}

1"Positive deviants" is defined as having a higher MAR and a lower MER than the respective median values. MAR, mean adequacy ratio per $2000 \mathrm{kcal}$; MER, mean excess ratio per $2000 \mathrm{kcal}$.

${ }^{2}$ Wilcoxon two-sample test.

${ }^{3}$ Chi-square test. 


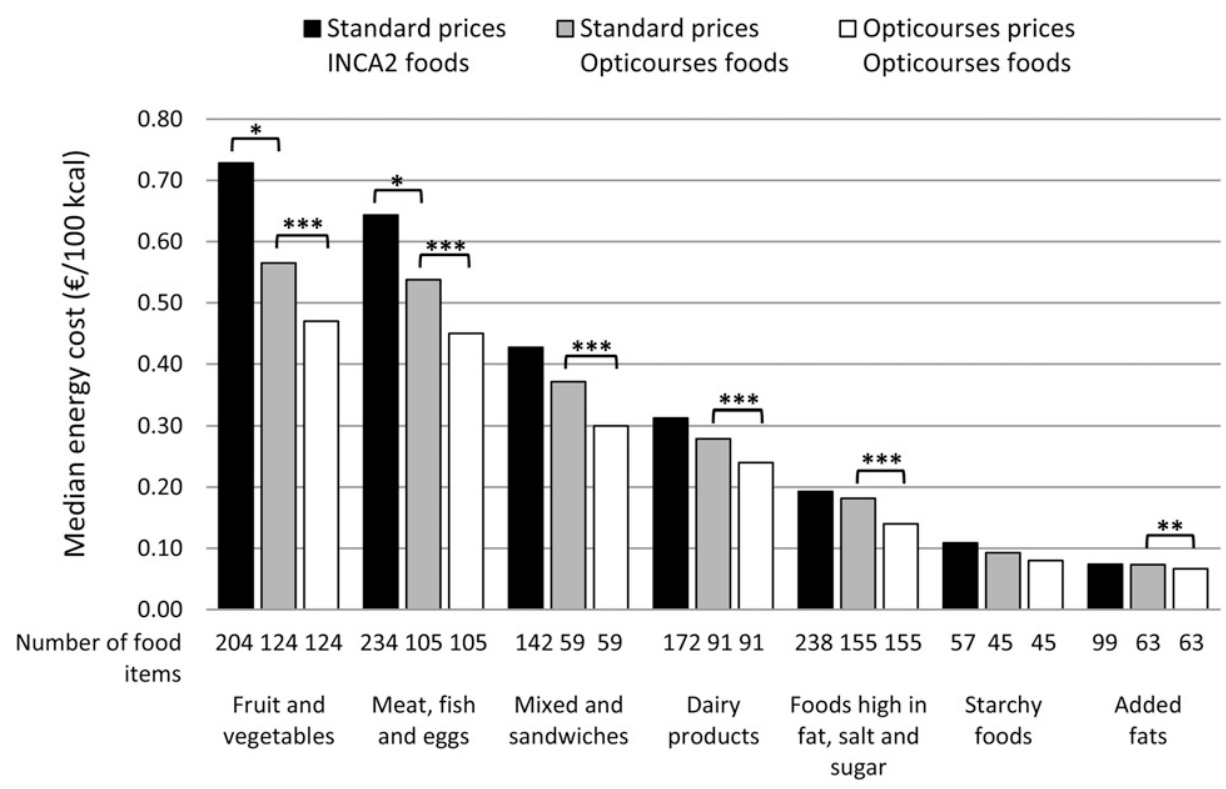

FIGURE 1 Median energy costs $(€ / 100 \mathrm{kcal})$ of $\boldsymbol{\square}$ all foods in the national INCA2 food database using the standard food prices database; $\square$ the foods purchased by Opticourses households using the standard food prices database; and $\square$ the foods purchased by Opticourses households using Opticourses prices; by food group, ranked from the most expensive to the least expensive. Comparisons between median energy costs of INCA2 foods and Opticourses foods at standard prices were made with Wilcoxon two-sample test for each food group. Comparisons between median energy costs of Opticourses foods at standard prices and at Opticourses prices were made with Wilcoxon's Matched-Pairs Signed Rank test for each food group. ${ }^{*} P<0.05, * * P<0.01, * * * P<0.0001$. INCA, Individuelle Nationale des Consommations Alimentaires.

\section{Relations between diet cost and nutritional quality}

MAR and MER were mutually independent and, as expected, ED was negatively correlated with MAR and positively correlated with MER (Table 2). Regardless of whether diet cost was estimated from the standard food prices database (i.e., estimated diet cost) or on the basis of actual expenditure (i.e., actual diet cost), it was correlated in the same way with nutritional quality of diet: positively with MAR and negatively with ED. A moreexpensive diet was nutrient rich and less energy dense, but there was no correlation with MER (Table 2).

\section{Purchase characteristics}

\section{Diet cost and nutritional quality}

The total mean energy purchased was $2450 \mathrm{kcal} / \mathrm{d}$ per person for a total mean edible weight of $1818 \mathrm{~g} / \mathrm{d}$ per person (excluding drinking water), with wide variability due to the collection method. The nutritional quality indicators show, on average, an ED of 200 $\mathrm{kcal} / 100 \mathrm{~g}, 74 \%$ of adequacy for the MAR, and $16 \%$ of excess for the MER (Table 3). Although actual and estimated diet costs were strongly correlated with one another (Spearman correlation: 0.84; Table 2), mean actual diet cost was significantly lower than mean estimated diet cost ( 3.65 vs. $4.77 € /$ d per person, respectively). The actual energy cost per $2000 \mathrm{kcal}$ was $3.03 €$ and was significantly lower than the energy cost estimated with standard food prices (4.00 €/2000 kcal) (Table 3).

As expected, food purchases of positive deviants had a significantly higher MAR, lower MER, and consequently lower ED than food purchases of other Opticourses households. There was no significant difference in total energy purchased, total edible weight, or weight of solid foods. Actual daily cost and actual energy cost (per $2000 \mathrm{kcal}$ ) were similar for positive deviants and other households, but estimated energy cost (per $2000 \mathrm{kcal}$ ) was significantly higher in purchases of positive deviants (Table 3 ). Compared with the rest of the population, the diets of positive deviants had higher amounts of 15 nutrients (of the 23 MAR nutrients) and lower contents of SFAs and free sugars but not sodium (Supplemental Table 1).

\section{Food choices}

Table 4 shows the mean amounts bought and expenditures for each food group and food category per $2000 \mathrm{kcal}$ of purchases. Meat, fish, and eggs were the main contributors to food expenditure, at $0.85 €$ per $2000 \mathrm{kcal}$. Starchy foods, fruit and vegetables, and foods high in fat, salt, and sugar contributed to an equal proportion of the diet cost, $\sim 0.50 €$ for each per 2000 kcal. Moreover, Table 4 compares food choices of positive deviants and the other households. The positive deviants purchased more fish and eggs, more starchy foods, especially more refined and unrefined grains, more fruit and vegetables, but less food high in fat, salt, and sugar, especially fewer sweets, soft drinks, and salty snacks, and fewer sandwiches and pizzas. The positive deviants purchased the same amount of dairy products, but

\section{TABLE 2}

Spearman correlations between estimated diet cost per $2000 \mathrm{kcal}$ and actual diet cost per $2000 \mathrm{kcal}$ and 3 indicators of nutritional qualityMAR, MER, and ED-in the Opticourses population ${ }^{1}$

\begin{tabular}{lcccc}
\hline \hline & MER & ED & Estimated diet cost & Actual diet cost \\
\hline MAR & 0.11 & $-0.70^{* * *}$ & $0.61^{* * *}$ & $0.58^{* * *}$ \\
MER & & $0.21^{*}$ & 0.17 & 0.15 \\
ED & & & $-0.46^{* * *}$ & $-0.41^{* * *}$ \\
Estimated diet cost & & & & $0.84^{* * *}$ \\
\hline
\end{tabular}

${ }^{1} n=91 . * P<0.05, * * * P<0.0001$. ED, dietary energy density, in kcal per $100 \mathrm{~g}$; MAR, mean adequacy ratio per $2000 \mathrm{kcal}$; MER, mean excess ratio per $2000 \mathrm{kcal}$. 
TABLE 3

Purchasing characteristics of Opticourses households in terms of nutritional quality and $\operatorname{cost}^{1}$

\begin{tabular}{|c|c|c|c|c|c|c|c|}
\hline & \multicolumn{2}{|c|}{ All $(n=91)$} & \multicolumn{2}{|c|}{ Positive deviants $^{2}(n=21)$} & \multicolumn{2}{|c|}{ Others $(n=70)$} & $P^{3}$ \\
\hline Total energy, $\mathrm{kcal} / \mathrm{d}$ per person & $2450 \pm 1572$ & $2173(1452-3060)$ & $2090 \pm 1030$ & 1956 (1439-2327) & $2557 \pm 1693$ & $2222(1575-3060)$ & 0.19 \\
\hline Weight of solid food, $g / d$ per person ${ }^{4}$ & $1188 \pm 857$ & $1012(669-1461)$ & $1241 \pm 615$ & $1021(846-1582)$ & $1173 \pm 921$ & $975(654-1444)$ & 0.16 \\
\hline $\mathrm{ED}, \mathrm{kcal} / 100 \mathrm{~g}$ & $200 \pm 47.0$ & $187(164-235)$ & $160 \pm 20.8$ & $163(143-172)$ & $212 \pm 46.3$ & $207(176-243)$ & $<0.0001$ \\
\hline MAR, $\%$ adequacy $/ 2000 \mathrm{kcal}$ & $73.9 \pm 9.37$ & $75.0(67.9-81.2)$ & $81.2 \pm 4.4$ & $81.2(77.5-84.0)$ & $71.7 \pm 9.4$ & $71.4(66.4-79.1)$ & $<0.0001$ \\
\hline Estimated diet cost & $4.77 \pm 3.21$ & $4.06(2.78-5.76)$ & $4.47 \pm 2.30$ & $3.96(2.86-5.40)$ & $4.85 \pm 3.45$ & $4.15(2.75-5.76)$ & 0.48 \\
\hline Actual diet cost & $3.65 \pm 2.54$ & $3.07(2.11-4.43)^{* * * *}$ & $3.34 \pm 1.93$ & $2.77(2.11-4.23)$ & $3.75 \pm 2.70$ & $3.23(2.13-4.61)$ & 0.35 \\
\hline \multicolumn{8}{|l|}{ Energy cost, $€ / 2000 \mathrm{kcal}$} \\
\hline Estimated diet cost & $4.00 \pm 1.23$ & $3.71(3.06-4.67)$ & $4.40 \pm 1.15$ & $4.50(3.26-5.29)$ & $3.88 \pm 1.24$ & $3.57(3.04-4.56)$ & 0.03 \\
\hline Actual diet cost & $3.03 \pm 0.95$ & $2.91(2.27-3.70)^{* * * *}$ & $3.17 \pm 0.87$ & $3.20(2.57-3.70)$ & $2.98 \pm 0.97$ & $2.86(2.19-3.68)$ & 0.18 \\
\hline
\end{tabular}

tended to buy less cheese. They bought the same amount of added fats. Table 4 also compares expenditures of positive deviants and others. The difference between positive deviants and others was comparable to the difference between food expenditure and food weights, which suggests that positive deviants and the other households purchased their food at the same price. To confirm our findings, we calculated actual mean prices per food group for positive deviants and for other households. Wilcoxon's matched-pairs comparison did not show any difference (data not shown).

\section{DISCUSSION}

This is the first study, to our knowledge, to assess the relation between the actual cost of diets and their nutritional quality. Based on household food purchases, the results confirm that the known positive association between diet nutritional quality and diet costs (1-5) exists even within a low-income population (6) and they show that this relation persists when using actual food expenditure. However, much variability in food-purchasing behavior was observed, so it was possible to identify positive deviants who purchased higher-quality diets at no additional cost and to characterize their food choices.

One strength of this study was the use of real food expenditure. Opticourses households actually spent $3.65 € / \mathrm{d}$ per person on food consumed at home, which is remarkably close to the mean national expenditure for food at home for households in the lowest quintile of socioeconomic conditions, as calculated by the French National Institute of Statistics and Economic Studies from the last French National Budget Survey (i.e., $3.85 € /$ d per person in 2005) (34). Compared with expenditure on food consumed at home in the general French population (i.e., $5.25 € / \mathrm{d}$ per person), the Opticourses population spent rather little on food. The use of standard food prices instead of prices actually paid by this population would overestimate their real expenditure on food by $\sim 1 € /$ d per person ( 4.77 vs. $3.65 €$ ). Previous studies also found relatively weak agreement between diet cost estimated with standard food prices and with prices actually paid by individuals (35-37). This important difference in daily diet costs can be explained by different food choices, as suggested by the comparison of the Opticourses food price database with the standard food price database. We highlighted 2 distinct strategies implemented by Opticourses households to economize their food budget: they selected the less-expensive food items within a food group and they purchased the cheapest options for a given food item. Indeed, in France, branded products were found to cost, on average, 2.5 times more than the cheapest version of the same product (38), which is why low-income households increasingly shop at discount food stores and to a larger extent than do affluent people (34). Yet, although food budgets in lowincome households are low, it represents a high proportion of their total budget, as predicted by Engel's law (39).

A positive correlation between diet nutritional quality and cost was observed regardless of whether energy cost was estimated from standard food prices or cash register receipts. Opticourses participants purchased less-expensive food, but the ranking of energy costs among food groups remained the same as in the standard food price database. As previously observed, low-energy-dense and nutrient-rich foods, such as fruit and vegetables or meat products, were the most expensive sources of calories, whereas energy-dense and nutrient-poor foods, such as foods high in fat, salt, and sugar; starchy foods; or added fats were the cheapest sources of calories $(40,41)$. This relation between food prices and nutritional quality among food products forms the basis of the positive association between food expenditure and nutritional quality. Because Opticourses participants had a small amount of money to spend on food, the higher energy costs of healthy food groups were likely to be a barrier to healthy eating. Incidentally, their food purchases showed less-favorable nutritional quality indicators (more energy dense and less nutrient rich) than the average French diet (32).

The selection process of positive deviants led to the identification of 21 participants who purchased higher-quality diets $(+13 \%$ of MAR, $-90 \%$ of MER, and $-22 \%$ of ED compared with the other households). In accordance with the positive 
TABLE 4

Opticourses-household purchases: mean amounts (g/2000 kcal) and expenditures (€/2000 kcal), by food group and food category, in descending order of expenditure $^{1}$

\begin{tabular}{|c|c|c|c|c|c|c|c|c|}
\hline & \multicolumn{3}{|c|}{ Quantities, g/2000 kcal } & \multicolumn{4}{|c|}{ Expenditure, $€ / 2000 \mathrm{kcal}$} & $P^{3}$ \\
\hline Red meat & $51.0 \pm 65.6$ & $44.9 \pm 33.4$ & $51.2 \pm 70.1$ & 0.22 & $0.39 \pm 0.47$ & $0.39 \pm 0.44$ & $0.37 \pm 0.45$ & 0.28 \\
\hline Poultry & $28.9 \pm 44.1$ & $28.5 \pm 39.6$ & $28.4 \pm 45.0$ & 0.42 & $0.17 \pm 0.26$ & $0.19 \pm 0.34$ & $0.16 \pm 0.22$ & 0.49 \\
\hline Fish and shellfish & $18.9 \pm 27.6$ & $32.6 \pm 39.4$ & $14.3 \pm 21.1$ & 0.02 & $0.17 \pm 0.20$ & $0.24 \pm 0.23$ & $0.14 \pm 0.18$ & 0.03 \\
\hline Offal & $1.06 \pm 3.86$ & $2.04 \pm 6.10$ & $0.75 \pm 2.84$ & 0.27 & $0.01 \pm 0.02$ & $0.01 \pm 0.03$ & $0.01 \pm 0.02$ & 0.28 \\
\hline Starchy foods & $386 \pm 183$ & $500 \pm 171$ & $344 \pm 168$ & 0.0002 & $0.52 \pm 0.29$ & $0.62 \pm 0.24$ & $0.48 \pm 0.30$ & 0.008 \\
\hline Refined grains & $287 \pm 172$ & $365 \pm 168$ & $258 \pm 163$ & 0.003 & $0.42 \pm 0.28$ & $0.50 \pm 0.23$ & $0.39 \pm 0.29$ & 0.02 \\
\hline Potatoes & $72.4 \pm 76.4$ & $91.5 \pm 103$ & $65.4 \pm 65.1$ & 0.27 & $0.07 \pm 0.07$ & $0.09 \pm 0.09$ & $0.06 \pm 0.05$ & 0.12 \\
\hline Legumes & $21.2 \pm 48.1$ & $27.9 \pm 59.9$ & $18.7 \pm 43.6$ & 0.26 & $0.02 \pm 0.07$ & $0.02 \pm 0.03$ & $0.02 \pm 0.07$ & 0.26 \\
\hline Unrefined grains & $5.29 \pm 21.5$ & $15.6 \pm 40.3$ & $1.98 \pm 5.01$ & 0.08 & $0.01 \pm 0.02$ & $0.02 \pm 0.03$ & $0.01 \pm 0.02$ & 0.09 \\
\hline HFSS & $199 \pm 140$ & $89.7 \pm 64.9$ & $228 \pm 139$ & $<0.0001$ & $0.48 \pm 0.33$ & $0.27 \pm 0.14$ & $0.54 \pm 0.33$ & $<0.0001$ \\
\hline Sweets & $50.6 \pm 33.7$ & $28.8 \pm 19.6$ & $56.2 \pm 34.0$ & 0.0001 & $0.22 \pm 0.15$ & $0.13 \pm 0.10$ & $0.24 \pm 0.16$ & 0.0003 \\
\hline Desserts & $32.7 \pm 51.1$ & $21.4 \pm 18.9$ & $35.1 \pm 54.8$ & 0.24 & $0.12 \pm 0.20$ & $0.09 \pm 0.08$ & $0.12 \pm 0.20$ & 0.38 \\
\hline Soft drinks & $105 \pm 118$ & $33.9 \pm 51.4$ & $124 \pm 123$ & 0.0001 & $0.09 \pm 0.13$ & $0.02 \pm 0.04$ & $0.11 \pm 0.13$ & $<0.0001$ \\
\hline Salty snacks & $6.1 \pm 9.4$ & $2.60 \pm 4.81$ & $7.08 \pm 10.1$ & 0.01 & $0.04 \pm 0.06$ & $0.01 \pm 0.02$ & $0.04 \pm 0.07$ & 0.01 \\
\hline Breakfast cereals & $4.75 \pm 8.11$ & $2.96 \pm 6.34$ & $5.22 \pm 8.45$ & 0.17 & $0.02 \pm 0.03$ & $0.01 \pm 0.02$ & $0.02 \pm 0.03$ & 0.15 \\
\hline Dairy products & $185 \pm 135$ & $215 \pm 177$ & $172 \pm 117$ & 0.30 & $0.30 \pm 0.19$ & $0.31 \pm 0.22$ & $0.29 \pm 0.19$ & 0.40 \\
\hline Cheese & $23.4 \pm 18.5$ & $19.1 \pm 19.0$ & $24.1 \pm 17.8$ & 0.07 & $0.16 \pm 0.14$ & $0.14 \pm 0.15$ & $0.16 \pm 0.13$ & 0.13 \\
\hline Milk & $121 \pm 120$ & $158 \pm 162$ & $108 \pm 101$ & 0.29 & $0.08 \pm 0.08$ & $0.11 \pm 0.11$ & $0.07 \pm 0.07$ & 0.16 \\
\hline Yogurt & $40.1 \pm 35.2$ & $38.5 \pm 41.3$ & $39.8 \pm 33.0$ & 0.32 & $0.06 \pm 0.06$ & $0.06 \pm 0.07$ & $0.06 \pm 0.05$ & 0.37 \\
\hline Mixed & $33.5 \pm 57.8$ & $19.7 \pm 52.8$ & $36.5 \pm 55.9$ & 0.004 & $0.16 \pm 0.29$ & $0.09 \pm 0.21$ & $0.18 \pm 0.29$ & 0.01 \\
\hline Sandwiches, pizza & $17.1 \pm 27.9$ & $10.1 \pm 27.5$ & $18.7 \pm 26.6$ & 0.01 & $0.10 \pm 0.17$ & $0.06 \pm 0.11$ & $0.11 \pm 0.18$ & 0.02 \\
\hline High-fat sauces & $3.57 \pm 6.64$ & $2.48 \pm 4.04$ & $3.90 \pm 7.23$ & 0.23 & $0.01 \pm 0.01$ & $0.01 \pm 0.01$ & $0.01 \pm 0.01$ & 0.22 \\
\hline Condiments & $14.5 \pm 22.1$ & $22.0 \pm 40.1$ & $12.3 \pm 12.2$ & 0.37 & $0.05 \pm 0.07$ & $0.08 \pm 0.13$ & $0.04 \pm 0.04$ & 0.26 \\
\hline
\end{tabular}

${ }^{1}$ Values are means \pm SDs. HFSS, foods high in fat, salt, and sugar; MAR, mean adequacy ratio; MER, mean excess ratio.

2"Positive deviants" is defined as having a higher MAR and a lower MER than the respective median values.

${ }^{3}$ Wilcoxon two-sample test.

deviance theory (14), the 21 positive deviants did not differ significantly from the other Opticourses participants in their household composition or their financial situation. Yet, they purchased more fish, eggs, fruit, vegetables, and starchy foods and fewer products high in fat, salt, and sugar than did the rest of the Opticourses population. Moreover, they purchased less cheese and fewer animal fats (butter and cream), although not significantly so. These food choices could contribute to an increase in energy costs (e.g., due to the higher cost of fruit, vegetables, and fish), but they actually did not. Indeed, for the positive deviants, we found an increase in energy costs estimated from standard food prices but not in actual energy costs. This showed that the use of the standard food price database would have failed to identify nutritionally favorable purchasing behavior with no increase in food budget. Positive deviants purchased higher-quality diets at no additional cost, either per day or per $2000 \mathrm{kcal}$, suggesting that they selected foods with good nutritional quality for their price, as defined by Maillot et al. (42). Compared with the rest of the Opticourses population, they did not buy more cheaply, but they made different choices. Although their choices did not completely adhere to all nutritional recommendations (MAR $<100 \%$ ), these households managed to have a healthier diet than the general adult population in France, with an equivalent MAR and DE and lower MER (32), showing that it is possible to improve one's diet on a limited budget. 
Opticourses participants were not asked to make an inventory of their food stocks at the beginning and end of the receipts collection to take changes into account (43). We assumed that there was no change in the average amounts of food stocks within all households, although some households certainly acquired more than they consumed and others less, using stocks to adjust their actual food intake, which is why we did not exclude any outlier on the basis of incomplete records and why dietary indicators, such as diet costs, MAR, and MER were expressed for each household per $2000 \mathrm{kcal}$ of purchases for statistical analysis. Indeed, there was a wide variability in the energy purchased per day and per person according to the receipts collected, and because these indicators are dependent on total energy they needed to be energy-adjusted to reflect diet quality.

This study has several limitations. First, a generic foodcomposition database was used, although actual food purchases were recorded. We assumed that there was no difference in nutrient composition between foods of a particular type (e.g., corn flakes), because results from several studies have shown that there is no systematic association between sale price and nutritional quality for food products of a particular type $(38,44,45)$. Second, foods bought and consumed away from home were not recorded. Although eating out represents $53 \%$ of food expenditure in the United States (46), it is far less common in France, and represents only $15 \%$ of food expenditure among the lowestincome decile (34). A third limitation was that food purchases from small shops and markets were difficult to record because receipts are often not given and it is more difficult for participants to remember exactly what they purchased and to write it down at home. This may apply particularly to fresh foods, such as fruit and vegetables. Hence, we may have underestimated the actual purchases of fruit and vegetables of Opticourses participants. Last, participants were recruited for an intensive nutrition education intervention. Thus, they were persons in financial difficulty but who were trying to overcome this and may have been more aware of nutritional concerns than the rest of the population of the northern districts of Marseille. In addition, collecting and noting receipts for $4 \mathrm{wk}$ is a highly demanding task, requiring participants to be motivated and involved over the long term. However, this limitation can be viewed as a strength because such a recruitment bias likely increased the probability of identifying positive deviants.

This study confirms that higher-quality diets are usually more expensive than lower-quality diets; however, households purchasing low-cost diets without sacrificing nutrition were identified. The healthy purchasing behavior of positive deviants confirms the relevance of interventions aimed at making foods with good nutritional quality for their price visible, available, and attractive to make the best nutritional use for those on a limited food budget.

The authors' responsibilities were as follows-LM: analyzed the data and drafted the manuscript; $\mathrm{CD}, \mathrm{HG}$, and ND: conceived the Opticourses intervention; ND: helped interpret the findings and contributed substantially to the writing of the manuscript; MSG and AM: organized Opticourses workshops and collected the data; and AL: participated in Opticourses workshops and recorded the data. No conflicts of interest were reported.

\section{REFERENCES}

1. Cade J, Upmeier H, Calvert C, Greenwood D. Costs of a healthy diet: analysis from the UK Women's Cohort Study. Public Health Nutr 1999;2:505-12.
2. Andrieu E, Darmon N, Drewnowski A. Low-cost diets: more energy, fewer nutrients. Eur J Clin Nutr 2006;60:434-6.

3. Bernstein AM, Bloom DE, Rosner BA, Franz M, Willett WC. Relation of food cost to healthfulness of diet among US women. Am J Clin Nutr 2010;92:1197-203.

4. Rehm CD, Monsivais P, Drewnowski A. The quality and monetary value of diets consumed by adults in the United States. Am J Clin Nutr 2011;94:1333-9.

5. Schröder H, Vila J, Marrugat J, Covas M-I. Low energy density diets are associated with favorable nutrient intake profile and adequacy in free-living elderly men and women. J Nutr 2008;138:1476-81.

6. Townsend MS, Aaron GJ, Monsivais P, Keim NL, Drewnowski A. Less-energy-dense diets of low-income women in California are associated with higher energy-adjusted diet costs. Am J Clin Nutr 2009; 89:1220-6.

7. Monsivais P, Drewnowski A. Lower-energy-density diets are associated with higher monetary costs per kilocalorie and are consumed by women of higher socioeconomic status. J Am Diet Assoc 2009;109: 814-22.

8. Aggarwal A, Monsivais P, Drewnowski A. Nutrient intakes linked to better health outcomes are associated with higher diet costs in the US. PLoS ONE 2012;7:e37533.

9. Darmon N, Drewnowski A. Does social class predict diet quality? Am J Clin Nutr 2008;87:1107-17.

10. Aggarwal A, Monsivais P, Cook AJ, Drewnowski A. Does diet cost mediate the relation between socioeconomic position and diet quality? Eur J Clin Nutr 2011;65:1059-66.

11. James WP, Nelson M, Ralph A, Leather S. Socioeconomic determinants of health: the contribution of nutrition to inequalities in health. BMJ 1997;314:1545-9.

12. McAllister M, Baghurst K, Record S. Financial costs of healthful eating: a comparison of three different approaches. J Nutr Educ 1994; 26:131-9.

13. Monsivais P, Rehm C, Drewnowski A. The DASH diet and diet costs among ethnic and racial groups in the United States. JAMA Intern Med 2013;173:1922-4.

14. Marsh DR, Schroeder DG, Dearden KA, Sternin J, Sternin M. The power of positive deviance. BMJ 2004;329:1177-9.

15. Vossenaar M, Mayorga E, Campos R, Anderson AS, Solomons NW. The positive deviance approach can be used to create culturally appropriate eating guides compatible with reduced cancer risk. J Nutr 2009;139:755-62.

16. DeWalt KM, D'Angelo S, McFadden M, Danner FW, Noland M, Kotchen JM. The use of itemized register tapes for analysis of household food acquisition patterns prompted by children. J Am Diet Assoc 1990;90:559-62.

17. Cullen K, Baranowski T, Watson K, Nicklas T, Fisher J, O'Donnell S, Baranowski J, Islam N, Missaghian M. Food category purchases vary by household education and race/ethnicity: results from grocery receipts. J Am Diet Assoc 2007;107:1747-52.

18. Rankin JW, Winett RA, Anderson ES, Bickley PG, Moore JF, Leahy M, Harris CE, Gerkin RE. Food purchase patterns at the supermarket and their relationship to family characteristics. J Nutr Educ 1998;30:81-8.

19. Ransley JK, Donnelly JK, Khara TN, Botham H, Arnot H, Greenwood DC, Cade JE. The use of supermarket till receipts to determine the fat and energy intake in a UK population. Public Health Nutr 2001;4: 1279-86.

20. Ransley JK, Donnelly J, Botham H, Khara T, Greenwood D, Cade J. Use of supermarket receipts to estimate energy and fat content of food purchased by lean and overweight families. Appetite 2003;41:141-8.

21. Darmon N, Gaigi H, Dubois C. Opticourses [home page] [cited 2014 Oct 27]. Available from: http://opticourses.fr/.

22. Dubuisson C, Lioret S, Touvier M, Dufour A, Calamassi-Tran G, Volatier J-L, Lafay L. Trends in food and nutritional intakes of French adults from 1999 to 2007: results from the INCA surveys. Br J Nutr 2010;103:1035-48.

23. Kantar Worldpanel. French household consumer panel-Kantar Worldpanel [cited 2014 Oct 27]. Available from: http://www. kantarworldpanel.com/global/Sectors.

24. Nelson M, Dyson P, Paul A. Family food purchases and home food consumption: comparison of nutrient contents. Br J Nutr 1985;54:373-87.

25. Ledikwe JH, Blanck HM, Khan LK, Serdula MK, Seymour JD, Tohill BC, Rolls BJ. Low-energy-density diets are associated with high diet quality in adults in the United States. J Am Diet Assoc 2006;106:1172-80. 
26. Drewnowski A, Monsivais P, Maillot M, Darmon N. Low-energydensity diets are associated with higher diet quality and higher diet costs in French adults. J Am Diet Assoc 2007;107:1028-32.

27. Ledikwe JH, Blanck HM, Khan LK, Serdula MK, Seymour JD, Tohill BC, Rolls BJ. Dietary energy density determined by eight calculation methods in a nationally representative United States population. J Nutr 2005;135:273-8.

28. Kant AK. Indexes of overall diet quality: a review. J Am Diet Assoc 1996;96:785-91.

29. Maillot M, Darmon N, Vieux F, Drewnowski A. Low energy density and high nutritional quality are each associated with higher diet costs in French adults. Am J Clin Nutr 2007;86:690-6.

30. Martin A. Apports nutritionnels conseillés pour la population française. [Recommended nutritional intakes for the French population.] 3rd ed. Paris: Lavoisier; 2001 (in French).

31. Madden JP, Goodman SJ, Guthrie HA. Validity of the 24-hr. recall: analysis of data obtained from elderly subjects. J Am Diet Assoc 1976;68:143-7.

32. Vieux F, Soler L, Touazi D, Darmon N. High nutritional quality is not associated with low greenhouse gas emissions in self-selected diets of French adults. Am J Clin Nutr 2013;97:569-83.

33. WHO/FAO Expert Consultation. Diet, nutrition and the prevention of chronic diseases. World Health Organ Tech Rep Ser 2003;916:1-149.

34. Accardo J, Bellamy V, Consalès G, Vidal G. Cinquante ans de consommation en france. [Fifty years of consumption in France.] 2009 Institut national de la statistique et des études économiques Editor. Paris. 233 pages. (in French).

35. Monsivais P, Perrigue MM, Adams SL, Drewnowski A. Measuring diet cost at the individual level: a comparison of three methods. Eur J Clin Nutr 2013;67:1220-5.

36. Timmins KA, Morris MA, Hulme C, Edwards KL, Clarke GP, Cade JE. Comparability of methods assigning monetary costs to diets: derivation from household till receipts versus cost database estimation using 4day food diaries. Eur J Clin Nutr 2013;67:1072-6.
37. Aaron GJ, Keim NL, Drewnowski A, Townsend MS. Estimating dietary costs of low-income women in California : a comparison of 2 approaches. Am J Clin Nutr 2013;97:835-41.

38. Darmon N, Caillavet F, Joly C, Maillot M, Drewnowski A. Low-cost foods: how do they compare with their brand name equivalents? A French study. Public Health Nutr 2009;12:808-15.

39. Engels F. The conditions of the working class in England. London: Penguin Books; 1845.

40. Darmon N, Darmon M, Maillot M, Drewnowski A. A nutrient density standard for vegetables and fruits: nutrients per calorie and nutrients per unit cost. J Am Diet Assoc 2005;105:1881-7.

41. Maillot M, Darmon N, Darmon M, Lafay L, Drewnowski A. Nutrientdense food groups have high energy costs: an econometric approach to nutrient profiling. J Nutr 2007;137:1815-20.

42. Maillot M, Ferguson EL, Drewnowski A, Darmon N. Nutrient profiling can help identify foods of good nutritional quality for their price: a validation study with linear programming. J Nutr 2008;138: 1107-13.

43. Nelson M, Bingham S. Assessment of food consumption and nutrient intake. In: Margetts BM, Nelson M, editors. Design concepts in nutritional epidemiology. 2nd ed. Oxford (United Kingdom): Oxford University Press; 1997. p. 123-69.

44. Cooper S, Nelson M. "Economy" line foods from four supermarkets and brand name equivalents: a comparison of their nutrient contents and costs. J Hum Nutr Diet 2003;16:339-47.

45. Menard C, Dumas C, Gillot N, Laurent L, Labarbe B, Ireland J, Volatier J-L. The French OQALI survey on dairy products: comparison of nutrient contents and other nutrition information on labels among types of brands. J Hum Nutr Diet 2012;25:323-33.

46. French SA, Wall M, Mitchell NR, Shimotsu ST, Welsh E. Annotated receipts capture household food purchases from a broad range of sources. Int J Behav Nutr Phys Act 2009;6:37. 